\title{
Rancang Bangun Network Monitoring Dan Bandwidth Monitoring Dengan Menggunakan Aplikasi Cacti Pada PT. XYZ
}

\author{
Anggoro Aryo P. ${ }^{1}$, Daniel Udjulawa ${ }^{2}$ \\ ${ }^{12}$ STMIK GI MDP; Jl. Rajawali No.14 Palembang Sumatera Selatan Indonesia, \\ Telp: +62-(711)-376400 \\ ${ }^{* 1}$ Program Studi Sistem Informasi, ${ }^{* 2}$ Program Studi Teknik Informatika, STMIK GI MDP, \\ Palembang \\ e-mail: ${ }^{1}$ anggoro_aryop@mdp.ac.id, ${ }^{2}$ daniel@mdp.ac.id
}

\begin{abstract}
Abstrak
Saat ini internet telah digunakan dalam berbagai aspek kehidupan manusia sehari-hari. Pemakaian internet tidak lepas dari perkembangan teknologi jaringan komputer sebagai penunjangnya. Sebagai penyedia jasa layanan internet PT. XYZ berusaha untuk memberikan layanan yang terbaik bagi pelanggannya dengan memanfaatkan teknologi jaringan komputer. Selain menggunakan perangkat jaringan dengan teknologi yang terbaru, PT. XYZ juga berusaha untuk meningkatkan kepercayaan kepada pelanggannya dengan memberikan layanan internet yang sesuai dengan kebutuhan yang diinginkan. Untuk meningkatkan layanannya, PT. XYZ memerlukan suatu Network Monitoring atau pemantauan jaringan serta memantau bandwidth agar dapat memantau perangkat jaringan serta mengevaluasi kinerja PT. XYZ dan umpan baliknya dari pelanggan. Protokol pada jaringan TCP/IP menggunakan SNMP. Rancang bangun network monitoring dan bandwith monitoring pada PT XYZ menggunakan aplikasi Cacti. Perancangan server Cacti dibangun dengan webserver Apache, dengan bahasa pemrograman PHP dan menggunakan basis data MySQL. Apache disini berfungsi sebagai webserver yang berguna untuk menjalankan PHP dan MySQL. PHP berfungsi untuk menjalankan skrip pembuatan grafik yang akan ditampilkan. Sedangkan MySQL digunakan sebagai penyimpan seluruh data yang dihasilkan oleh aplikasi cacti. Selain itu juga ditanamkan paket RRDTool yang akan digunakan untuk menampilkan data yang didapat melalui port SNMP yang disimpan dalam database MySQL dan dijalankan oleh bahasa pemrograman PHP, lalu ditampilkan dalam bentuk grafik. Diharapkan dengan adanya Network Monitoring dan Bandwidth Monitoring ini dapat mengetahui kualitas jaringan dan seberapa besar penggunaan bandwidth di PT. XYZ.
\end{abstract}

Kata kunci: Jaringan Komputer, Internet, Bandwidth, PHP, MySQL, Apache, RRDTool, SNMP, Cacti.

\begin{abstract}
Today the internet has been used in various aspects of everyday human life. The use of the internet can not be separated from the development of computer network technology as a support. As an internet service provider PT. XYZ strives to provide the best service for its customers by utilizing computer network technology. In addition to using network devices with the latest technology, PT. XYZ also strives to increase trust in its customers by providing internet services that suit their desired needs. To improve its services, PT. XYZ requires a
\end{abstract}


Network Monitoring or network monitoring and monitoring bandwidth so that it can monitor network devices and evaluate the performance of PT. XYZ and feedback from customers. Protocols on TCP / IP networks use SNMP. Design network monitoring and bandwidth monitoring at PT XYZ using the Cacti application. Cacti server design is built with Apache webserver, with PHP programming language and using MySQL database. Apache here functions as a webserver that is useful for running PHP and MySQL. PHP functions to run graphical scripts that will be displayed. While MySQL is used as a storage for all data generated by the Cacti application. In addition, the RRDTool package is also embedded which will be used to display data obtained through SNMP ports stored in the MYSQL database and run by the PHP programming language, then displayed in graphical form. It is expected that with the existence of Network Monitoring and Bandwidth Monitoring this can determine the quality of the network and how much bandwidth is used at PT. XYZ.

Keywords: Jaringan Komputer, Internet, Bandwidth, PHP, MySQL, Apache, RRDTool, SNMP, Cacti.

\section{PENDAHULUAN}

Dunia teknologi informasi saat ini begitu pesatnya, sehingga semua orang dalam berkomunikasi pun dapat dengan cepat dan hampir tanpa kendala. Hal ini dapat dipastikan karena adanya internet yang menjadi alat bantunya menjadi pendukung dalam segala aspek kegiatan manusia. Perkembangan Internet pun perlu didukung dengan perkembangan Teknologi Jaringan, mengingat banyak hal yang dapat dilakukan dengan adanya internet tersebut. Teknologi jaringan akan mempengaruhi kecepatan proses dalam berkomunikasi. Banyak perusahaan penyedia jasa layanan internet, berusaha mengembangkan diri dengan memberikan layanan kecepatan proses beserta monitoringnya. Untuk monitoring yang penting untuk dilakukan adalah manajemen jaringan. Manajemen jaringan akan dapat memonitor, memantau dan merencanakan jaringan Komputer dan sistemnya. Proses monitoring sendiri merupakan bagian dari manajemen proyek, sehingga monitoring baik montoring jaringan, maupun monitoring bandwidth akan sangat penting dalam menjaga kualitas layanan internet terhadap pengguna. PT. XYZ merupakan perusahaan yang bergerak dalam bidang pelayanan jasa internet. Demi menjaga kepercayaan publik maka mereka berusaha untuk meningkatkan layanan. Dalam meningkatkan pelayanan tersebut diperlukan suatu Network Monitoring atau pemantauan jaringan agar dapat memantau perangkat-perangkat jaringan yang ada dan juga Bandwidth Monitoringyakni pemantauan bandwidth yang digunakan dalam rangka memantau pemakaian bandwidthdan mengevaluasi kinerja PT. XYZ. Selain dari pemantauan tersebut PT. XYZ juga perlu melihat umpan balik dari pelanggannya. Rancang bangun dari network monitoring dan bandwidth monitoringnya menggunakan aplikasi Cacti. Aplikasi Cacti merupakan aplikasi pemantau yang berbasis Simple Network Management Protocol (SNMP). Hampir semua peralatan jaringan telah mendukung penggunaan SNMP. Protokol tersebut memudahkan pengelola dalam memantau dan melaporkan penggunaan bandwidth internet. Hal ini akan dapat dilihat kapastitas Bandwith yang digunakan akan sesuai atau tidak guna memenuhi kebutuhan para pengguna. Perancangan untuk Cacti dibangun dengan webserver Apache serta bahasa skripnya menggunakan PHP. Untuk Basis data digunakan basis data MySQL. Dengan menggunakan MYSQL secara otomatis Apache juga harus tertanam disini. Apache berfungsi sebagai webserver yang berguna untuk menjalankan PHP dan MySQL. MySQL digunakan sebagai penyimpan seluruh data yang dihasilkan oleh aplikasi cacti. Selain

Aryo P., et.al (Rancang Bangun Network Monitoring dan Bandwidth Monitoring dengan Menggunakan Aplikasi Cact $i$ Pada PT. XYZ) 
itu juga ditanamkan paket RRDTool yang akan digunakan untuk menampilkan data yang didapat melalui port SNMP.

\section{LANDASAN TEORI}

Dasar teori yang digunakan dalam penelitian ini, sangat mendukung dalam merancang dan membangun monitoring jaringan dan monitoring bandwidth menggunakan sebuah aplikasi.

\subsection{Manajemen Jaringan}

Manajemen jaringan adalah kemampuan untuk memonitor, mengontrol, dan merencanakan suatu jaringan komputer dan komponen sistem. Monitoring jaringan merupakan bagian dari manajemen jaringan. Hal yang paling mendasar dalam konsep manajemen jaringan adalah tentang adanya manajer atau perangkat yang memanajemen serta perangkat yang di atur. Dalam implementasinya ada berbagai macam arsitektur manajemen jaringan yang didasarkan pada tipe dan ukuran masing-masing. Ada dua arsitektur yang dapat digunakan yaitu manajemen terpusat (centralized management) dan manajemen menyebar (distributed management) [1].

\subsection{Simple Network Management Protocol (SNMP)}

Simple Network Management Protocol atau disingkat SNMP adalah sebuah protokol apikasi pada jaringan TCP/IP yang menangani manajemen jaringan. Protokol ini didesain sehingga pengguna dapat dengan mudah memantau kondisi jaringan komputer [2]. Pemantauan kondisi jaringan dapat dilakukan dengan cara pengumpulan nilai-nilai informasi dari kondisi jaringan secara jarak jauh atau menggunkan satu pusat pengamatan.

\subsection{Network Monitoring System}

Network monitoring System Atau NMS merupakan tool untuk melakukan monitoring/pengawasan pada elemen-elemen dalam jaringan komputer. Fungsi dari NMS adalah melakukan pemantauan terhadap kualitas SLA (Service Level Agreement) dari Banwidth yang digunakan [3]. Hasil dari pantauan tersebut biasanya dijadikan bahan dalam pengambilan keputusan oleh pihak manajemen, disisi lain digunakan oleh administrator jaringan (technical person) untuk menganalisa apakah terdapat kejanggalan dalam operasional jaringan.

\subsection{Bandwidth Monitoring}

Bandwidth monitoring merupakan pemantauan akan pemakaian Bandwidth. Bandwidth adalah suatu nilai konsumsi transfer data yang dihitung dalam bit/detik atau yang biasanya di sebut dengan bit per second (bps), antara server dan client dalam waktu tertentu. Atau bisa didefinisikan sebagai lebar cakupan frekuensi yang dipakai oleh sinyal dalam medium transmisi [4]. Fungsi bandwidth adalah untuk menghitung transaksi data.

\subsection{Aplikasi Cacti}

Cacti merupakan frontend yang lengkap untuk RRDTool (Round-Robin Database Tool), Cacti menyimpan semua informasi yang diperlukan untuk membuat grafik dan populasinya di dalam database MySQL. Frontend Cacti dibuat sepenuhnya denganPHP [5]. Seiring dengan kemampuan untuk mempertahankan konsistensi Grafik, Sumber-sumber Data dan Arsip Round Robin dalam database, Cacti juga menangani pengumpulan data dan juga mendukung SNMP untuk membuat grafik lalu lintas data dengan MRTG (The Multi Router Traffic Grapher). 


\section{METODE PENELITIAN}

Dalam rancang bangun ini, digunakan beberapa tahapan teknik pengerjaan sebagai berikut: a. Analisis Kebutuhan

Didalam analisis kebutuhan ini dibagi menjadi 2 bagian, yaitu analisis kebutuhan perangkat keras (hardware) dan analisis kebutuhan perangkat lunak (software).

Analisis kebutuhan perangkat keras (hardware) yakni berupa server. Server ini nantinya akan digunakan terpisah dengan fungsi-fungsi server yang lain, mengingat pentingnya data yang didapat dari hasil network monitoring dan bandwidth monitoring.Data tersebut dapat digunakan untuk kebutuhan seperti analisis pemakaian bandwidth, analisis availability, dan analisis reliability.Pada analisis kebutuhan perangkat lunak (software) ini digunakan yang digunakan untuk menjalankan aplikasi Cacti, seperti sistem operasi atau aplikasi lainnya.

b. Instalasi dan Konfigurasi

Pada tahap ini nantinya akan dikerjakan instalasi dan konfigurasi perangkat lunak seperti sistem operasi yang akan digunakan dan aplikasi pendukung lainnya untuk menjalankan aplikasi Cacti. Selanjutnya akan dilakukan pengujian apakah aplikasi Cacti ini dapat berjalan untuk mengambil data perangkat jaringan dan pemakaian bandwidth melalui SNMP.

c. Implementasi dan Pengujian

Pada tahap implementasi dan pengujian, servernetwork monitoring dan bandwidth monitoring di implementasikan kedalam jaringan yang dimiliki PT. XYZ dan nantinya akan dilakukan beberapa pengujian apakah hasil dari bandwidth monitoring sesuai dengan pemakaian internet pada PT. XYZ dan pelanggan internet.

d. Hasil dan Pelaporan

Pada tahap ini akan disajikan hasil yang didapat dari implementasi dan pengujian yang berupa grafik yang telah dibuat oleh $\mathrm{Cacti}$, selain itu dapat dilihat seberapa besar akurasi yang didapat dengan melihat dari database pemakaian bandwidth dari perangkat jaringan yang akan diuji.

\section{ANALISIS KEBUTUHAN, PERANCANGAN, IMPLEMENTASI DAN PENGUJIAN}

\subsection{Analisis Kebutuhan}

4.1.1 Analisis Kebutuhan Perangkat Keras (Hardware)

Perangkat keras yang digunakan sebagai berikut:

a. Komputer dengan spesifikasi Processor Intel ${ }^{\circledR}$ Pentium ${ }^{\circledR}$ G4560, 3,5Ghz, 3MB Cache, LGA1151.

b. Memori 4GB.

c. Harddisk dengan kapasitas 500 GB.

\subsubsection{Analisis Kebutuhan Perangkat Lunak (Software)}

Kebutuhan perangkat lunak (Software) yang akan digunakan sebagai server network monitoring dan bandwidth monitoring ini sebagai berikut:

a. Sistem Operasi Linux CentOS.

b. Aplikasi pemrograman web PHP Versi 5.4.16

c. Aplikasi database menggunakan MariaDB Versi 5.5.60

d. Aplikasi web server menggunakan Apache Versi 2.4.6

e. Aplikasi administrasi database menggunakan phpMyAdmin Versi 4.3.13.3

f. Aplikasi RRDTools

g. Aplikasi SNMP

Aryo P., et.al (Rancang Bangun Network Monitoring dan Bandwidth Monitoring dengan Menggunakan Aplikasi Cact $i$ Pada PT. XYZ) 
h. Aplikasi Cacti Versi 0.8.8h

4.2 Perancangan

4.2.1 Alur Perancangan

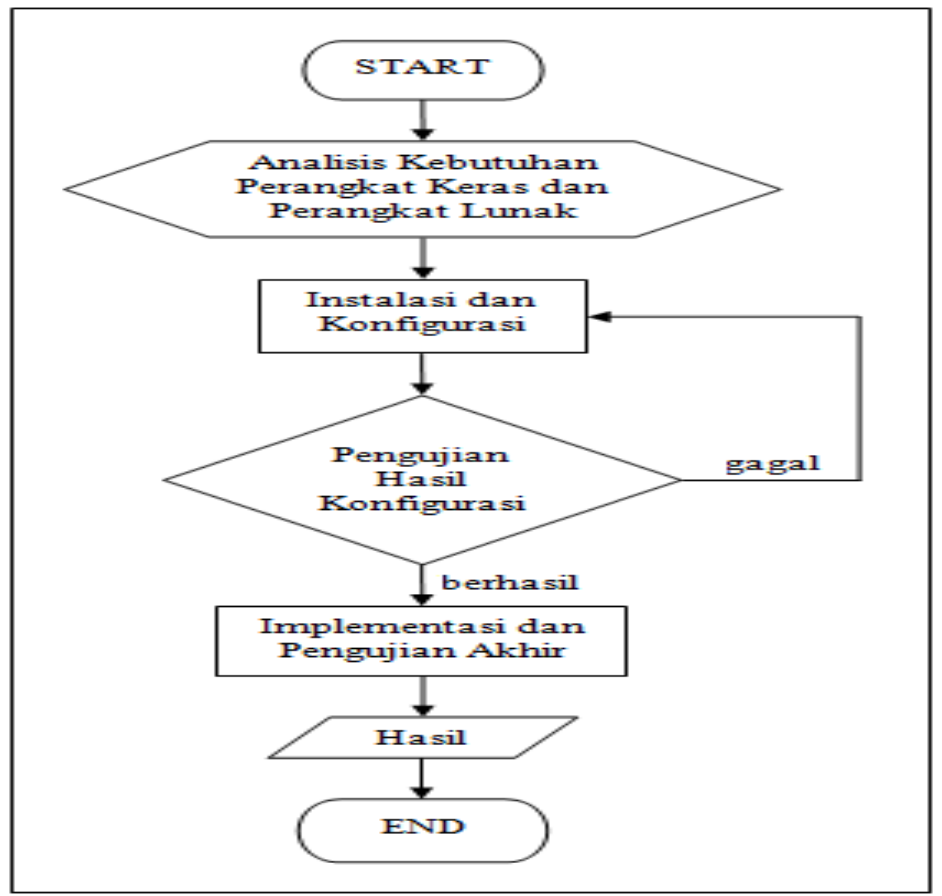

Gambar 1. Alur Rancang Bangun Server Network Monitoring dan Bandwidth Monitoring

\subsubsection{Topologi Server Network Monitoring dan Bandwidth Monitoring}

Topologi yang digunakan untuk membangun Server Network Monitoring dan Bandwidth Monitoring menggunakan topologi star, menggunakan IP Address publik dan akan menggunakan subdomain dari PT. XYZ. Selanjutnya Server Network Monitoring dan Bandwidth Monitoring ini akan disebut sebagai Server Cacti.Penempatan Server Cacti dapat dilihat pada Gambar 2, tampak Server Cacti ini berdiri sendiri, serta menggunakan komputer tersendiri dan terpisah dengan server lain. Didalam penempatannya diharapkan agar Server Cacti ini akan dapat memonitor perangkat jaringan yang ada pada PT. XYZ seperti routerrouter, radio access point, akses internet dari NAP (Network Access Provider) menuju PT. XYZ dan juga akses internet dari PT. XYZ menuju ke pelanggan dengan memantau radio station dan router yang ada di sisi pelanggan [6].

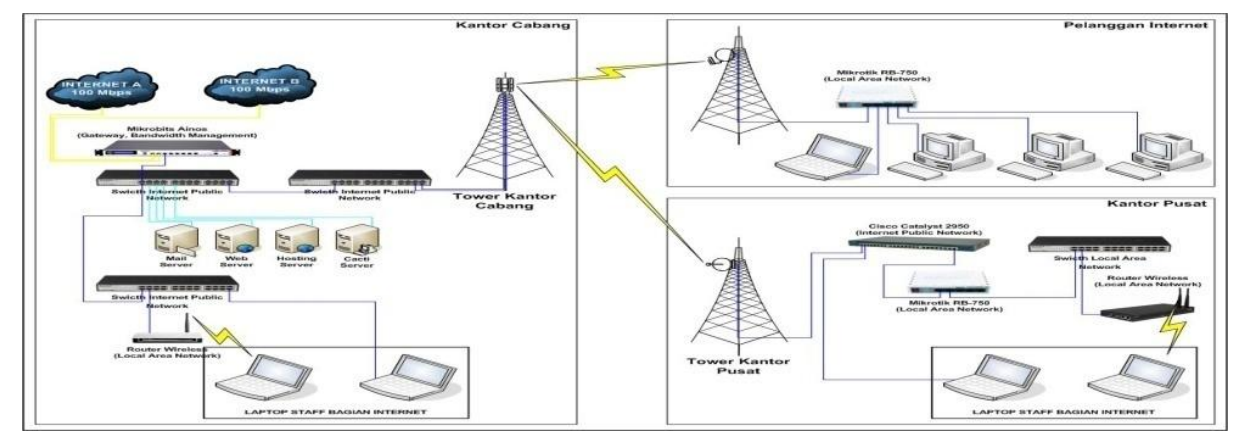

Gambar 2. Topologi Penempatan Server Network Monitoring dan Bandwidth Monitoring

Aryo P., et.al (Rancang Bangun Network Monitoring dan Bandwidth Monitoring dengan Menggunakan Aplikasi Cact iPada PT. XYZ) 
Server Cacti ini juga digunakan untuk memantau link internet yang menuju ke kantor pusat dimana lokasinya berbeda dengan lokasi penempatan Server Cacti yang berada di kantor cabang. Nantinya Server Cacti ini juga akan dapat memantau perangkat router yang ada di kantor pusat sehingga dapat dilihat seberapa besar pemakaian internet yang ada di kantor pusat tersebut.

\subsubsection{Instalasi dan Konfigurasi}

Pada tahap ini akan dilakukan instalasi sekaligus konfigurasi perangkat lunak yang akan digunakan sebagai server network monitoring dan bandwidth monitoring. Sebagai Server network monitoring dan bandwidth monitoring, nantinya akan menggunakan aplikasi Cacti [7], dimana diperlukan beberapa aplikasi lainnya yang menjadi prasyarat sebelum instalasi Cacti dilakukan.

a. Instalasi Linux CentOS 7

Untuk sistem operasi yang digunakan sebagai server network monitoring dan bandwidth monitoring ini adalah sistem operasi Linux CentOS Release 7 dengan spesifikasi server 64 bit [7]. Kemudian dilakukan update untuk memperbarui kernel atau sistemnya.

b. Update Linux CentOS 7

Setelah selesai dilakukan instalasi sistem operasi Linux CentOS 7, kemudian dilakukan update kernel dengan versi terbaru. Kernel merupakan sistem file inti yang ada didalam sistem operasi Linux yang mengatur fungsi dari perangkat-perangkat keras (hardware) pada komputer atau server yang digunakan. Setelah dilakukan update kernel diharapkan nantinya sistem operasi Linux yang sudah diinstalasi dapat mengenal dan meningkatkan kinerja dari perangkat keras versi terbaru yang dipakai sebagai server.

Tabel 1. Perintah Update Kernel

[root@localhost ]\# yum -y update

c. Konfigurasi Hostname, IP Address dan DNS

Langkah selanjutnya adalah pemberian nama dari server yang telah diinstalasi dengan sistem operasi Linux CentOS 7. Pemberian nama server ini dimaksudkan agar nantinya nama server ini dapat digunakan sebagai domain pada saat mengakses server ini baik secara remote maupun secara web base.

Tabel 2. Perintah Konfigurasi Hostname

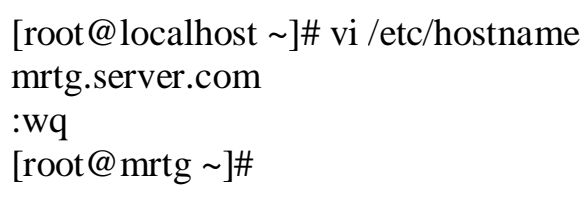

Kemudian dilakukan konfigurasi IP Address dan DNS pada server ini, agar server ini nantinya dapat terkoneksi ke internet dan dapat diakses menggunakan IP Address yang telah dikonfigurasi pada server ini. Selain itu pemberian IP Address juga dimaksudkan nantinya aplikasi Cacti dapat mengambil data SNMP pada perangkat-perangkat jaringan yang ada. 
Tabel 3. Perintah Konfigurasi IP Address dan DNS

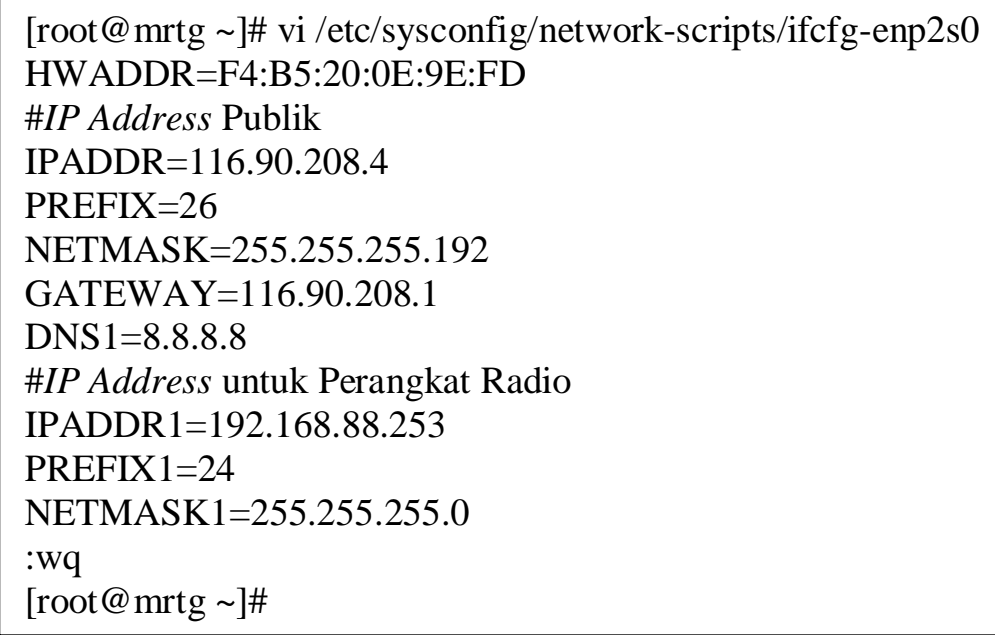

d. Instalasi Aplikasi Pemrograman Web PHP Versi 5.4.16

Pada tahap ini dilakukan instalasi Aplikasi Pemrograman Web PHP dimana versi PHP yang digunakan adalah PHP Versi 5.4.16.

Tabel 4. Perintah Instalasi PHP Versi 5.4.16

[root@mrtg ]\# yum -y install php-mysql php-pear php-common php-gd php-devel php php-mbstring php-cli php-intl php-snmpphp-mysqli

e. Instalasi Aplikasi Database MariaDB Versi 5.5.60

Database yang digunakan untuk server ini adalah menggunakan $M y S Q L$ dengan aplikasi MariaDB Versi 5.5.60. Pada tahap ini instalasi dilakukan dengan langkah sebagai berikut:

Tabel 5. Perintah Instalasi MariaDB Versi 5.5.60

$$
\text { [root@mrtg ]\# yum -y install mariadb-server }
$$

Kemudian fungsikan agar aplikasi MariaDB ini secara otomatis dapat berjalan pada saat awal pertama kali sistem operasi Linux berjalan. Masukkan perintah untuk menjalankan aplikasi MariaDB seperti yang terlihat pada Tabel 6.

Tabel 6. Perintah Menjalankan Servis MariaDB

$$
\begin{aligned}
& \text { [root@mrtg ]\# systemctl enable mariadb } \\
& \text { [root@mrtg ]\# systemctl start mariadb }
\end{aligned}
$$

f. $\quad$ Instalasi Aplikasi Web Server Apache Versi 2.4.6

Pada tahap ini dilakukan instalasi aplikasi Web Server Apache Versi 2.4.6 dan dilakukan pengaturan konfigurasi pada aplikasi Apache ini. 
Tabel 7. Perintah Instalasi Apache Versi 2.4.6

[root@mrtg ]\# yum -y install httpd httpd-devel

Kemudian lakukan konfigurasi Apache Versi 2.4.6 dengan membuka file konfigurasinya yang terletak pada directory /etc/httpd/conf/httpd.conf .

Tabel 8. Pengaturan Konfigurasi Apache pada file httpd.conf

\begin{tabular}{|l|}
\hline [root@ mrtg ]\# vi /etc/httpd/conf/httpd.conf \\
DocumentRoot "/home/www/html" \\
<Directory "/home/www/html"> \\
AllowOverride None \\
Require all granted \\
</Directory> \\
<Directory "/home/www/html"> \\
Options Indexes FollowSymLinks \\
AllowOverride None \\
Require all granted \\
</Directory> \\
:wq \\
[root@ mrtg ] ]
\end{tabular}

Pada pengaturan konfigurasi Apache ini seperti yang terlihat pada Tabel 8, untuk defaultdirecotry file web nya terletak pada folder /home/www/html. Nantinya seluruh file aplikasi Cacti akan dimasukkan kedalam folder /home/www/html tersebut.

Tabel 9. Perintah Menjalankan Servis Apache

$$
\begin{aligned}
& \text { [root@mrtg ]\# systemctl enable httpd } \\
& \text { [root@mrtg ]\# systemctl start httpd }
\end{aligned}
$$

Setelah selesai melakukan pengaturan konfigurasi Apache, kemudian fungsikan agar aplikasi Apache ini dapat berjalan secara otomatis pada saat awal pertama kali sistem operasi Linux berjalan, seperti terlihat pada Tabel 9. Kemudian masukkan perintah untuk menjalankan aplikasi Apache tersebut.

g. Instalasi Aplikasi phpMyAdmin Versi 4.3.13.3

Pada tahap ini akan dilakukan instalasi aplikasi phpMyAdmin Versi 4.3.13.3, dimana aplikasi ini berfungsi sebagai administrasi database MySQL yang mengontrol pengaturan database berbentuk webinterface [8]. Untuk melakukan instalasi phpMyAdmin Versi 4.3.13.3 dapat dilakukan dengan menggunakan perintah seperti pada Tabel 10.

Tabel 10. Perintah Instalasi phpMyAdmin

$$
\text { [root@ mrtg ]\# yum -y install phpMyAdmin }
$$

h. Instalasi Aplikasi RRD Tool dan Aplikasi SNMP

Langkah selanjutnya adalah instalasi aplikasi RRDTool dan SNMP. Aplikasi RRDTool berfungsi sebagai data logging, graphing system dan round-robin database tool. Aplikasi 
SNMP merupakan pengembangan dari protocol SNMP (Simple Network Management Protocol) [9] yang digunakan untuk memantau fungsi dan kinerja dari perangkat jaringan, perangkat komputer dan perangkat lainnya yang terhubung didalam jaringan komputer. Untuk instalasi RRDTool dan SNMP bisa dilakukan secara bersamaan dengan menggunakan perintah seperti yang terlihat pada Tabel 11. Setelah selesai melakukan instalasi RRDTool dan SNMP, kemudian fungsikan agar aplikasi SNMP ini dapat berjalan secara otomatis pada saat awal pertama kali sistem operasi Linux berjalan.

\section{Tabel 11. Perintah Instalasi RRDTool dan SNMP}

[root@mrtg ]\# yum -y install rrdtool net-snmp net-snmp-utils net-snmp-libs [root@mrtg ]\# systemctl enable snmpd [root@mrtg ]\# systemctl start snmpd

i. Instalasi Aplikasi Cacti Versi 0.8.8h

Pada tahap ini dilakukan instalasi aplikasi Cacti, dimana aplikasi yang digunakan pada server ini adalah Cacti Versi 0.8.8h [10]. Instalasinya dilakukan secara manual, dengan mengunduh aplikasi Cacti Versi 0.8.8h ini terlebih dahulu, kemudian nanti akan di ekstrak kedalam folder dimana web akan ditampilkan.

Tabel 12. Perintah Mengunduh Aplikasi Cacti Versi 0.8.8h

[root@mrtg ]\# wget https://www.cacti.net/downloads/cacti-0.8.8h.tar.gz

Aplikasi Cacti dapat diunduh pada alamat situs https://www.cacti.net/downloads dan masih dalam bentuk yang terkompresi. Untuk mengunduh dari alamat situs dapat dilakukan dengan perintah wget seperti yang terlihat pada Tabel 12.Setelah mengunduh file aplikasi Cacti tersebut, kemudian lakukan ekstraksi file tadi sehingga nantinya dapat diletakkan pada folder utama tempat seluruh file web diletakkan. Untuk melakukan ekstraksi file dapat menggunakan perintah seperti pada Tabel 13.

Tabel 13. Perintah Ekstraksi File Cacti-0.8.8h.tar.gz

[root@mrtg ]\# tar cacti-0.8.8h.tar.gz

Kemudian pindahkan seluruh file yang telah di ekstraksi tersebut ke dalam folder utama tempat seluruh file web diletakkan. Pada server ini folder seluruh file websiteterletak pada folder /home/www/html. Untuk memindahkan seluruh file yang telah di ekstraksi tadi dapat menggunakan perintah seperti pada Tabel 14.

Tabel 14. Perintah Memindahkan Seluruh File Hasil Ekstraksi Cacti-0.8.8h.tar.gz

[root@mrtg ]\# cd cacti-0.8.8h

[root@mrtg cacti-0.8.8h]\#mv*/home/www/html/

Langkah selanjutnya adalah membuat database dan user database untuk Cacti, yang nantinya semua data log perangkat-perangkat yang akan dimonitor tersimpan. Kemudian berikan izin dan hak istimewa bagi user database tersebut untuk mengakses database Cacti yang telah dibuat tadi. Langkah perintahnya adalah sebagai berikut: 
Tabel 15. Perintah Membuat Database Cacti

[root@mrtg ]\# mysql -u root -p

Enter password:

MariaDB [(none)]> create database cactidatabase;

MariaDB [(none)]> CREATE USER 'cactiuser' @ 'localhost' IDENTIFIED BY 'cactipassword'; MariaDB [(none)]> grant all privileges on cactidatabase.* to cactiuser@localhost ;

MariaDB [(none)]> flush privileges;

Tabel 16. Perintah Impor dan Memberikan Akses ke Tabel mysql_test_data_timezone.sql

[root@mrtg ]\# mysql -u root -p mysql </usr/share/mysql/mysql_test_data_timezone.sql

Enter password:

[root@mrtg ]\# mysql -u root -p

Enter password:

MariaDB [(none)]> GRANT SELECT ON mysql.time_zone_name TO cactiuser@localhost;

MariaDB [(none)]> flush privileges;

Langkah selanjutnya adalah impor file SQL aplikasi Cacti yang ada didalam folder/home/www/html/ kedalam database MySQL yang telah dibuat pada Tabel 15 sebelumnya. Perintah yang akan dilakukan adalah seperti yang terlihat pada Tabel 17 sebagai berikut:

Tabel 17. Perintah Impor File SQL Cacti kedalam Databasecactidatabase

[root@mrtg ]\# mysql -u root -p cactidatabase </home/www/html/cacti.sql

Kemudian lakukan pengaturan konfigurasi database untuk aplikasi Cacti yang akan diakses menggunakan web. Untuk pengaturannya dapat dilihat pada Tabel 18 sebagai berikut:

Tabel 18. Pengaturan Konfigurasi Database Aplikasi Cacti

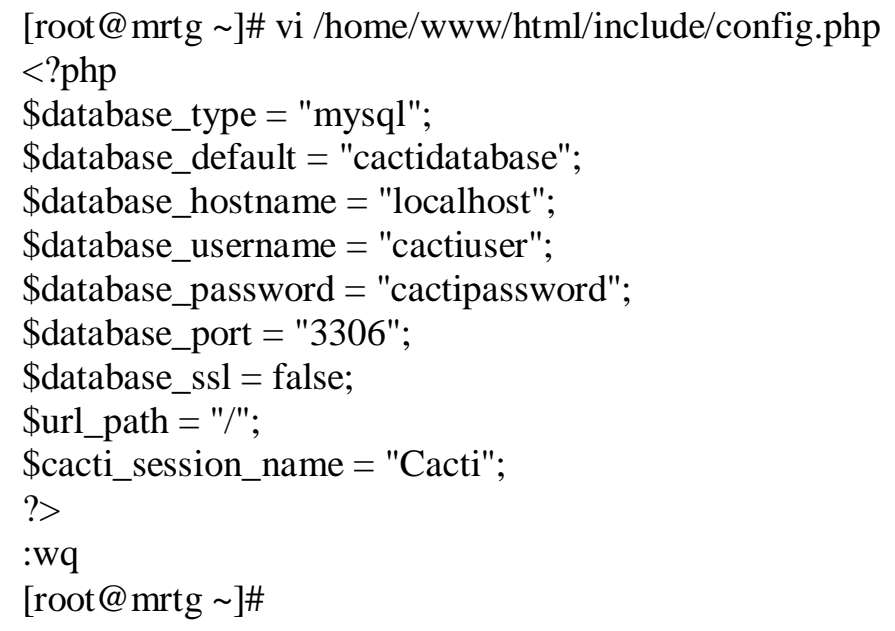

Tahap selanjutnya adalah pengaturan zona waktu yang digunakan dalam aplikasi Apache didalam server cacti ini. Pengaturan zona waktu ini dengan mengedit file php.ini didalam folder 
/etc/. Zona waktu yang digunakan adalah Asia/Jakarta, dimana perintah yang digunakan adalah sebagai berikut:

Tabel 19. Perintah Pengaturan Zona Waktu

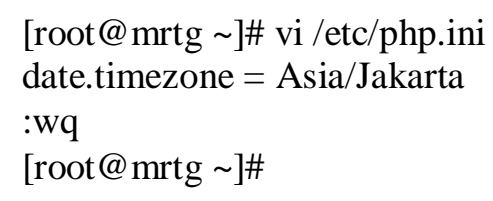

Langkah berikutnya adalah pengaturan Firewall untuk aplikasi Cacti, dimana firewall ini akan mengizinkan secara umum untuk dapat mengakses server cacti ini. Sehingga nantinya server ini terbuka dan dapat diakses secara umum melalui internet. Perintah untuk pengaturan Firewall dapat dilihat pada Tabel 20.

Tabel 20. Perintah Pengaturan Firewall

[root@ mrtg ]\# firewall-cmd --permanent --zone=public --add-service=http [root@ mrtg ]\# firewall-cmd --reload

Kemudian tahap berikutnya buat agar aplikasi Cacti ini berjalan secara terjadwal untuk dapat mengambil data dari perangkat yang akan di monitoring. Untuk itu edit file crontab yang ada pada sistem operasi Linux. Langkah pengaturannya seperti terlihat pada Tabel 21.

Tabel 21. Perintah Pengaturan Jadwal Menjalankan Aplikasi Cacti

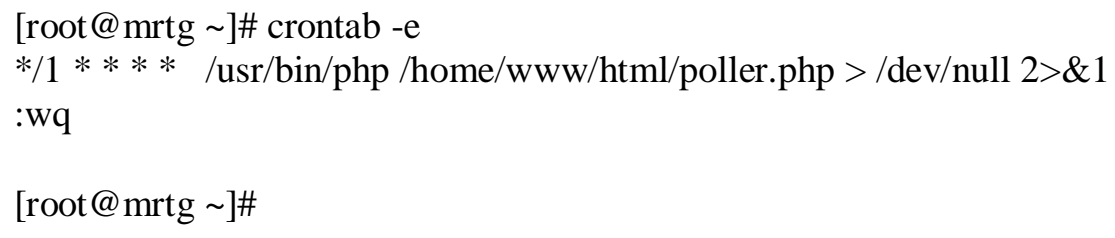

Setelah seluruh langkah diatas selesai dilakukan, restart ulang Apache, MariaDB, dan SNMP agar berjalan sesuai dengan pengaturan dan konfigurasi yang sudah dilakukan sebelumnya. Perintah untuk melakukan restart aplikasi Apache, MariaDB dan SNMP adalah sebagai berikut:

Tabel 22. Perintah RestartAplikasi Apache, MariaDB dan SNMP

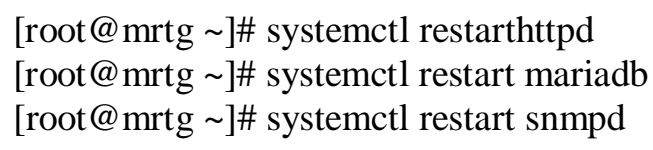

Tahap berikutnya adalah melakukan instalasi Cacti yang telah diletakkan didalam default folder web. Untuk instalasi Cacti ini dapat dilakukan dengan cara membuka aplikasi browser pada komputer user, kemudian masukkan IP Address publik yang telah di atur didalam server cacti ini. 
Selanjutnya akan ada konfirmasi pengaturan directoryRRDTool, PHP, SNMPWalk, SNMPGet, SNMPBulkWalk, SNMPGetNext dan Cacti.log. Seluruh pengaturan directory ini sudah menjadi standar ketika dilakukan instalasi Cacti. Kemudian terdapat menu pilihan untuk menggunakan Net-SNMP 5.X atau UCD-SNMP 4.X dan versi RRDTool yang akan digunakan. Untuk secara defaultnya gunakan Net-SNM 5.x dan RRDTool 1.0x. Untuk pilihan pengaturannya dapat dilihat pada Gambar 3.

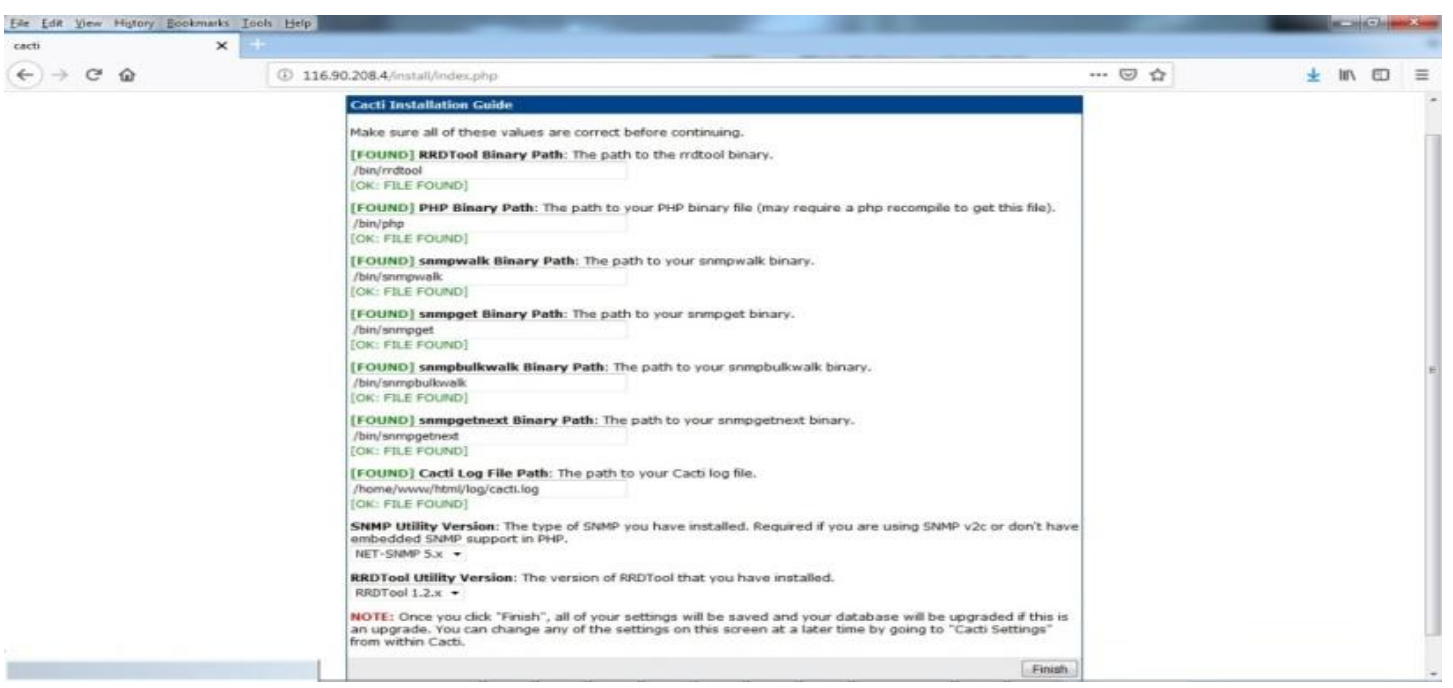

Gambar 3. Pengaturan pada Instalasi Cacti

Selanjutnya setelah instalasi aplikasi Cacti ini selesai, maka akan tampil halaman awal dari penggunaan aplikasi Cacti. Disini terlihat seluruh menu terletak pada sebelah kiri, dengan Menu Utama adalah console dan graphs. Aplikasi Cacti ini telah siap untuk digunakan dengan penggunaan standar sesuai dengan versi aplikasi Cacti yang diinstalasikan pada server ini.

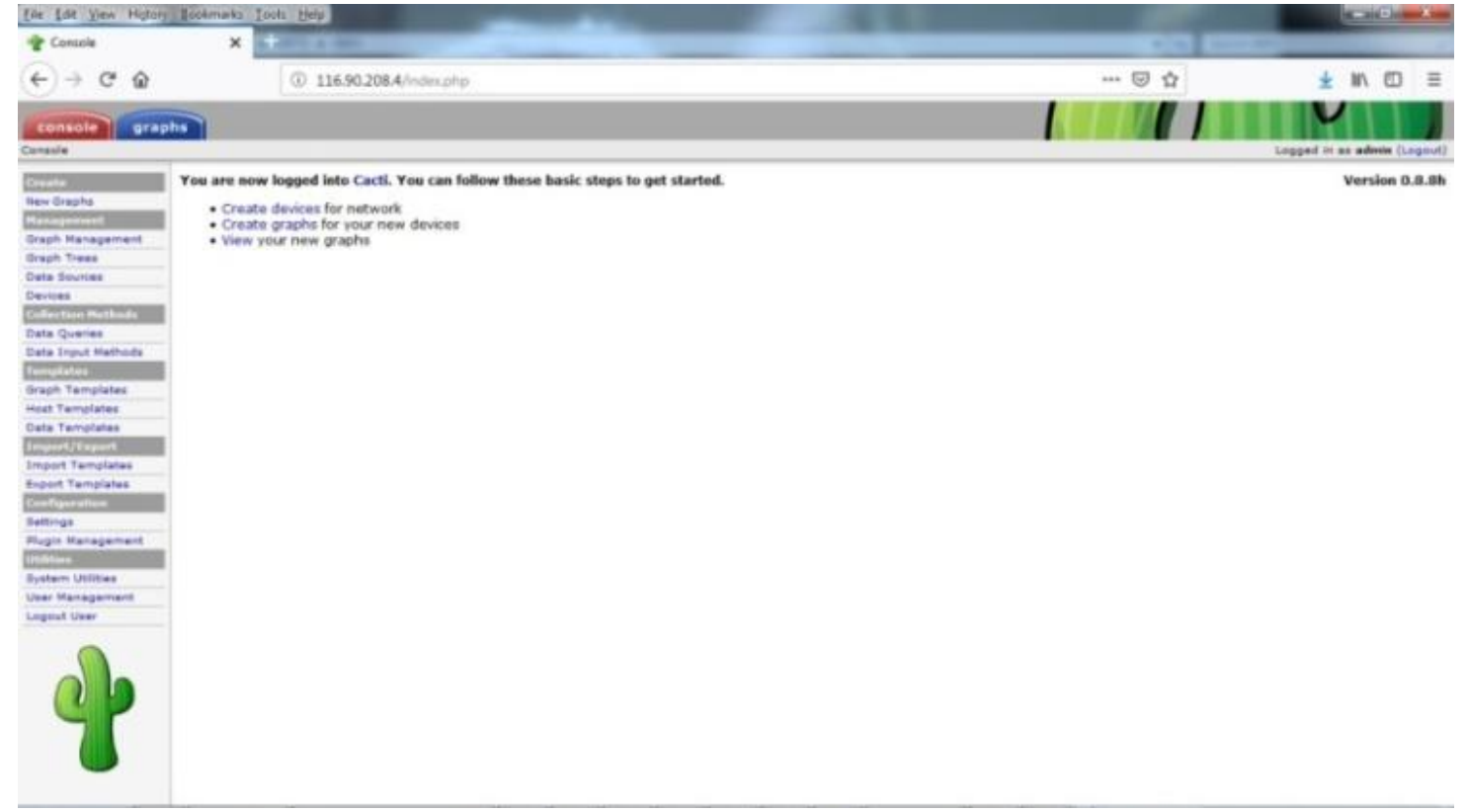

Gambar 4. Tampilan Awal Aplikasi Cacti

Aryo P., et.al (Rancang Bangun Network Monitoring dan Bandwidth Monitoring dengan Menggunakan Aplikasi Cact iPada PT. XYZ) 


\subsection{Implementasi dan Pengujian}

Pada tahap implementasi dan pengujian ini dilakukan penambahan perangkat jaringan yang akan di monitor. Sebagai contoh perangkat yang akan dimonitor adalah Router Mikro Bits Ainos, yang merupakan router yang diproduksi oleh Mikrotik [11]. Perangkat Router Mikro Bits Ainos yang digunakan oleh PT. XYZ ini berfungsi sebagai routergateway, firewall dan bandwidth management yang mengatur penggunaan seluruh IP Address Publik yang diberikan ke pengguna dan pelanggan internet. Sebelum menambahkan Router Mikro Bits Ainos ini kedalam aplikasi Cacti, perlu dilakukan beberapa pengaturan pada Router Mikro Bits Ainos tersebut berupa pengaturan SNMP Community yang nantinya akan dibaca oleh server Cacti. SNMP Community ini nantinya akan disamakan pada saat penambahan perangkat yang akan dimonitor oleh server Cacti, sehingga Router Mikro Bits Ainos ini dapat dimonitor penggunaanya. Untuk pengaturan SNMP Community pada perangkat Router Mikro Bits Ainos dapat dilihat pada Gambar 5.

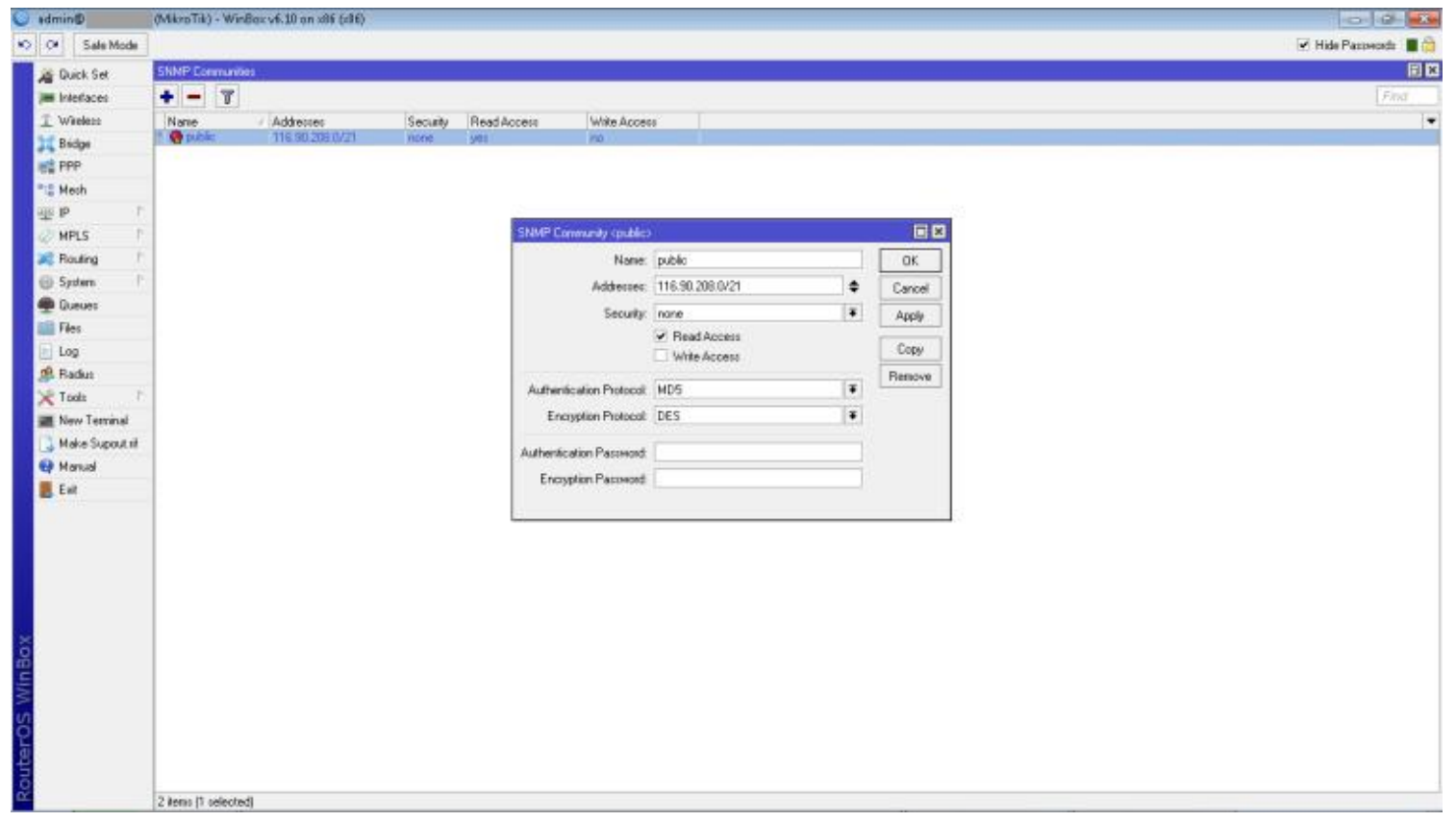

Gambar 5. Pengaturan SNMP Community pada Router MikroBits Ainos

Selanjutnya pada aplikasi Cacti, lakukan penambahan devices dengan memberikan deskripsi nama host yang nantinya akan ditampilkan, kemudian masukkan IP Address yang digunakan pada Router Mikro Bits Ainos. Template yang digunakan adalah Generic SNMPenabled Host, metode pendeteksian ketika perangkat down gunakan SNMP Uptime, versi SNMP gunakan Version 2, dan gunakan SNMP Community yang telah di atur didalam Router Mikro Bits Ainos sebelumnya yaitu public [12]. Langkah ini dapat dilihat pada Gambar 7. 


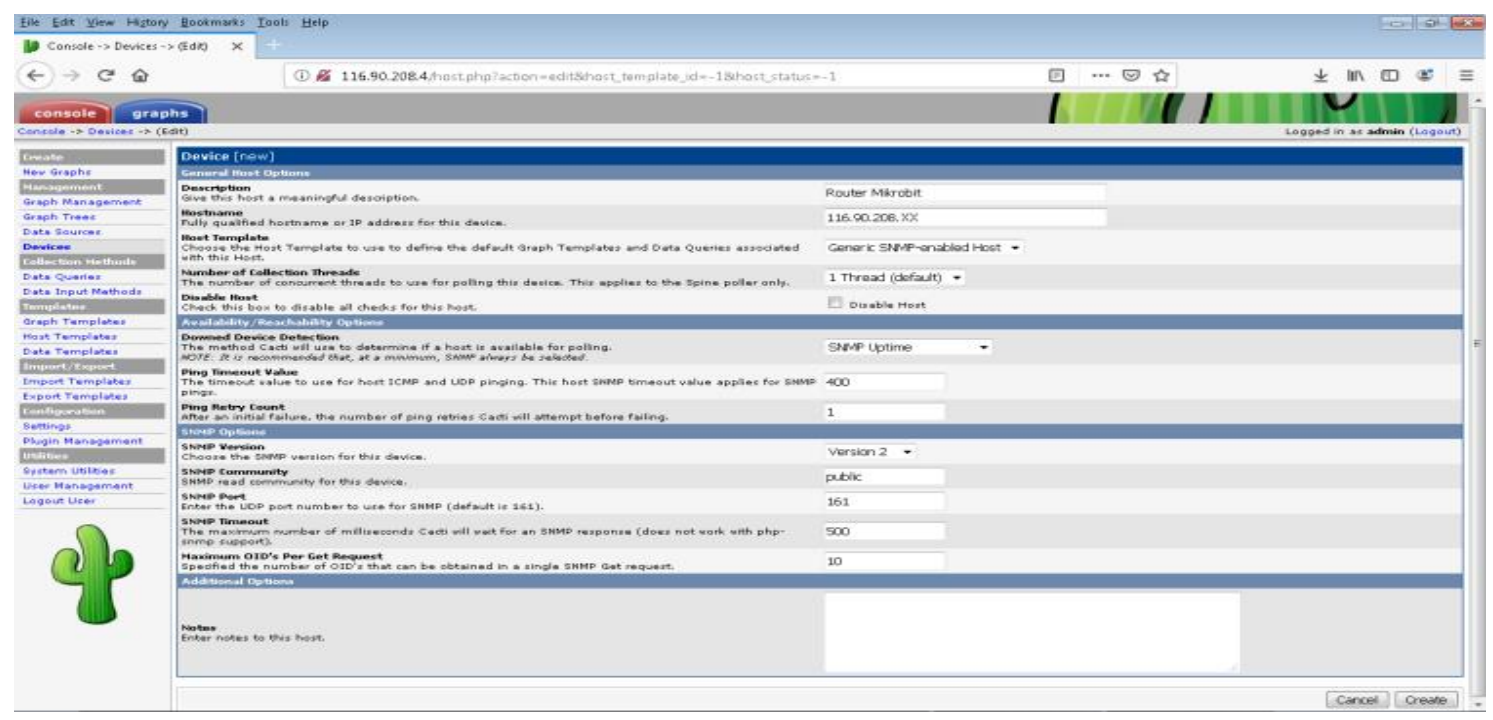

Gambar 6. Tahapan Penambahan Perangkat yang Akan Dimonitor

Setelah dilakukan penambahan devices atau perangkat jaringan, maka grafik yang akan ditampilkan berdasarkan interface yang akan dimonitor. Selain itu dari seluruh interface yang ada pada perangkat tersebut dapat dipilih mana yang akan ditampilkan dalam bentuk grafik sesuai dengan kebutuhan. Pada Router MikroBits Ainosyang akan dimonitor ini terdapat 8 interface dengan inisial yang digunakan berupa ethyang berarti interface ethernet, dimana seluruh interface ini digunakan sesuai dengan kebutuhan dari PT. XYZ. Untuk interface pertama adalah ethl digunakan sebagai input dari NAP atau Network Access Provider yang pertama yang menyediakan internet dengan kapasitas bandwidth 100 Mbps. Eth3 digunakan juga sebagai input internet dari NAP kedua dengan kapasitas bandwidth $100 \mathrm{Mbps}$ [13]. Eth3, eth5, eth7, eth8 digunakan sebagai akses internet yang akan diberikan ke pelanggan yang menggunakan IP address publik, dimana keempat port ethernet ini dibuat menjadi bridge dan menjadi interface baru dengan inisial bridge. Selanjutnyaeth2 dan eth4 tidak digunakan. Untuk tampilan grafik dari masing-masing port interface tersebut dapat dilihat pada Gambar 7. 


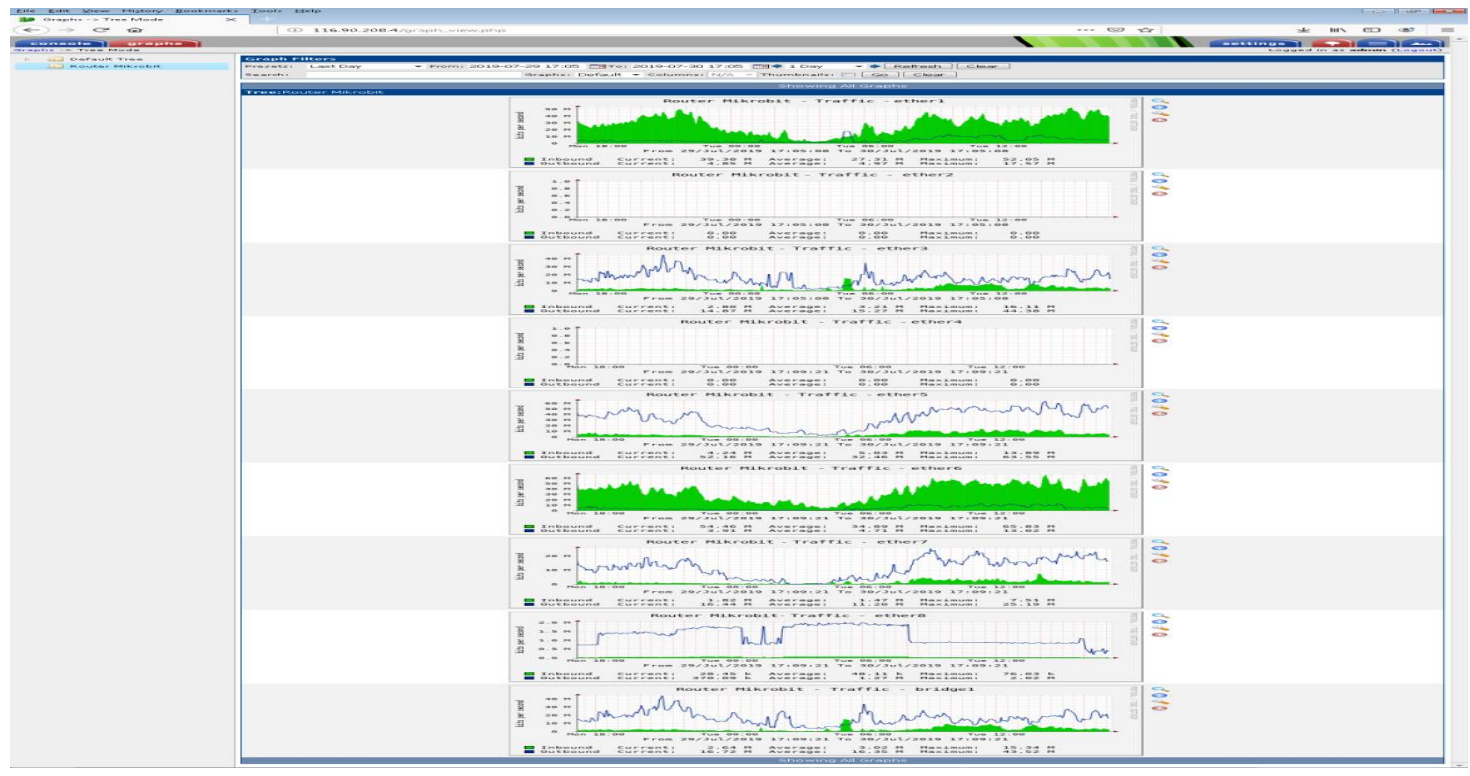

Gambar 7. Grafik yang Ditampilkan Berdasarkan Interface Pada Router MikroBits Ainos

Selain grafik, hasil monitoringpemakaian bandwidth dari perangkat ini juga akan disimpan secara realtime dengan jarak waktu penyimpanan setiap 5 menit dan dapat diunduh dalam bentuk format file .csv, serta dapat dilihat dengan menggunakan aplikasi Microsoft Excel. Sebagai contoh data pemakaian pada interface ethl yang telah diunduh dapat dilihat pada Gambar 8.

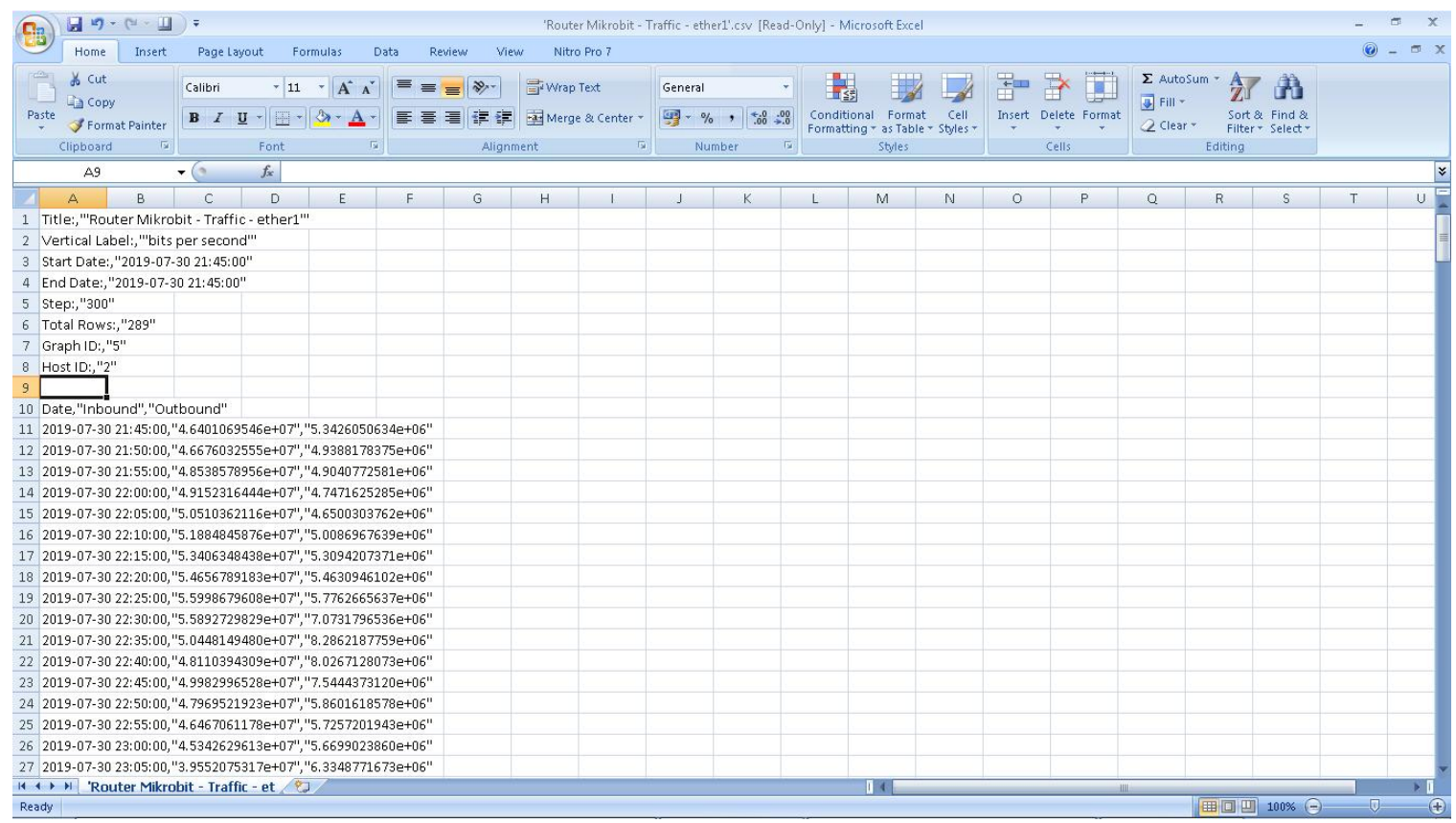

Gambar 8. Grafik yang Ditampilkan Berdasarkan Interface Pada Router MikroBits Ainos 


\section{KESIMPULAN}

Aplikasi Cacti merupakan salah satu cara yang dapat digunakan sebagai network monitoring dan bandwidth monitoring dengan memanfaatkan jaringan komputer yang ada, meskipun tidak secara realtime per menit akan tetapi dapat dimanfaatkan sebagai bentuk dokumentasi tentang penggunaan suatu fasilitas dan perangkat jaringan yang ada [6]. Hasil dokumentasi yang terbentuk dari aplikasi Cacti ini berupa grafik penggunaan bandwidth dan database hasil dokumentasi tersebut dapat diunduh berupa file .csv dengan jarak penyimpanan dokumentasi pemakaian setiap 5 menit. Dalam penelitian ini aplikasi Cacti hanya dimanfaatkan dalam bentuk grafik, meskipun fasilitas yang tersedia dari aplikasi Cacti ini memiliki pluginplugin lain yang dapat dimanfaatkan lebih banyak lagi dan harus dilakukan instalasi plugin terlebih dahulu.Selain itu database hasil dokumentasi yang dihasilkan dari aplikasi Cacti ini dapat dimanfaatkan untuk melakukan analisis penggunaan bandwidth perhari perminggu atau perbulan dan analisa kinerja perangkat jaringan (Grade of Service) yang ada di PT. XYZ.

\section{SARAN}

Dalam penggunaannya, aplikasi Cacti ini akan melakukan nerwork monitoring dan bandwidth monitoring pada perangkat jaringan komputer yang ada. Semakin banyak perangkat yang akan dimonitor maka diperlukan kemampuan komputer yang lebih besar yang akan digunakan sebagai server untuk aplikasi Cacti ini. Aplikasi Cacti ini dapat diakses oleh pengguna yang berbeda-beda, sehingga diperlukan klasifikasi user cacti berdasarkan fungsinya. Selain itu diperlukan juga aplikasi pendukung untuk dapat mengamankan server ini dari akses orang yang tidak berkepentingan, dengan memberikan firewall agar data yang tersimpan didalam server ini dapat terjamin ketersediaannya dan dapat dimanfaatkan untuk keperluan analisa yang lain.

\section{DAFTAR PUSTAKA}

[1] Hui Lee, Kwang 1994, “A Distributed Network Management Syatem”, Proceeding IEEE, Korea Research Foundation .

[2] G Mauro, Douglas 2005, “Essential SNMP Second Edition”, O'Reilly Media, Sebastopol.

[3] Fachruddin, Farid 2009, Implementasi Sistem Monitoring SLA Bandwidth Dalam Aplikasi Cacti, http://202.6.229.23/Download/artikel/cacti.pdf.

[4] Sora N 2015, Pengertian Bandwidth dan Fungsinya Secara Jelas, [online] Pengertian Apapun, Tersedia di: http://www.pengertianku.net/2015/05/pengertian-bandwidth-danfungsinya.html [Diakses 16 Januari 2018] (Sora N, 2015)

[5] Elizabeth Naramore, Jason Gerner, Yann Le Scouarnec, Jeremy Stolz, Michael K. Glass, 2005, Beginning PHP5, Apache, and MySQL® Web Development, Wiley Publishing, Inc., Indianapolis, Indiana.

[6] Insan. Bayunadi 2013, Network Monitoring Service Berbasis Simple Network Management Protocol Menggunakan Aplikasi Cacti, TRANSMISI,15,(4),2013,198.

Aryo P., et.al (Rancang Bangun Network Monitoring dan Bandwidth Monitoring dengan Menggunakan Aplikasi Cact $i$ Pada PT. XYZ) 
[7] Cacti Documentation, 2019, https://docs.cacti.net

[8] Andrew S. Tanenbaum, David J. Wetherall 2011, Computer Networks (Fifth Edition), Pearson Education, Inc., Publishing as Prentice Hall, Boston, Massachusetts.

[9] Tobias Oetiker, 2019, RRD Tool Tutorial, https://oss.oetiker.ch/rrdtool/tut/rrdtutorial.en.html

[10] What is Cacti?, 2019, https://www.cacti.net/what_is_cacti.php

[11] Kundu, Dinangkur., Ibrahim Lavlu, S.M, 2009, Cacti 0.8 Network Monitoring, Packt Publishing.

[12] phpMyAdmin Documentation 2019, https://buildmedia.readthedocs.org/media/pdf/phpmyadmin/latest/phpmyadmin.pdf

[13] Simple Network Management Protocol (SNMP) 2019, http://www.net-snmp.org 